\title{
Revisiting the Difficult Airway with special reference to the new Difficult Airway Society Guidelines
}

\section{Nel}

Specialist anaesthetist, Department of Anaesthesia, Chris Hani Baragwanath Academic Hospital, University of Witwatersrand, South Africa

Corresponding author, email: neldorinka@gmail.com

\section{Introduction}

Anaesthetists all over the world are doing millions of intubations every year. In about $6 \%$ of cases, they will encounter a "difficult airway".1 Between 2-8\% of cases may be associated with a poor view of the laryngeal inlet, ${ }^{2}$ while failure to achieve intubation is rather uncommon at 1-3 per 1000.2 The American Society of Anesthetists (ASA) defines a difficult airway as a clinical scenario in which a conventionally trained anesthesiologist experiences difficulty with facemask ventilation of the upper airway, difficulty with tracheal intubation or both. ${ }^{3}$ These difficulties may range from the case where simple airway maneuvers will improve the situation to the dangerous and feared scenario of "can't intubate, can't ventilate.

\section{Different aspects of the difficult airway}

Many people think that a difficult airway is purely the airway that is difficult to intubate. In fact there are much more to a difficult airway than just intubation. The different aspects to the difficult airway are: ${ }^{3,4,5}$

- Difficult facemask ventilation

- Difficult supra-glottic airway device placement

- Difficult laryngoscopy

- Difficult intubation

- Difficult surgical airway.

It is thus important to evaluate the airway with these aspects in mind. Certain airway features will have an influence on one of these aspects, while others may influence more than one aspect.

By the end of your airway assessment, you should be able to answer the following three questions:

- Will I be able to ventilate the patient using a facemask?

- Will I be able to intubate the patient with conventional methods?

- Will I be able to rescue the patient with a surgical airway if I land in a "can't intubate, can't ventilate" scenario?

\section{Airway evaluation}

Preoperative assessment of the airway is essential in every case $\mathrm{e}^{5}$ presenting for anaesthesia even if the planned technique will not include airway instrumentation. If a regional or neuraxial technique fails, or if the patient has to be intubated as part of resuscitation efforts, the anaesthetist has to know what to expect during airway management and must be able to deal with that airway even in an emergency situation. If a difficult airway is identified preoperatively, the team has to decide whether they have the capacity to deal with such an airway or whether the patient needs to be referred to a higher centre that has the resources and expertise to manage the patient appropriately. A lack of expertise in rescuing an airway should be a contraindication for the use of neuraxial anaesthesia. If a difficult airway is identified and the anaesthetist will not be able to intubate the airway should the need arises, he or she cannot ignore the problem by assuming that intubation will definitely not be needed.

This article will not deal with the anticipated difficult airway.

Part of the airway assessment is to identify the relative risk of aspiration ${ }^{5}$ and to take appropriate measures to decrease such a risk. In high-risk cases, cricoid pressure should be part of airway management. 5

If the difficult airway is both relatively common and potentially very dangerous, why is it that we still encounter the unanticipated difficult airway? The answer will have to address multiple aspects. Airway assessment is often not done properly and in some instances, not done at all. It may be that the examiner failed to pick up certain important clues to a potential difficult airway or failed to recognise the significance of an abnormal finding. However, possibly the most important reason is the poor specificity and sensitivity of current parameters in predicting the difficult airway. This makes airway assessment somewhat unreliable. ${ }^{5,6}$ El-Ganzouri et $\mathrm{al}^{6}$ had developed a multi-variate tool that combines some of the parameters to improve the ability to predict the ease of airway management. The model evaluates 7 variables and gives each variable a score between 0 and 2 . A score of $\geq 4$ may be associated with a difficult airway. 
The variables are mouth opening, thyromental distance, Mallampati score, ${ }^{7}$ neck movement, ability to prognath, body weight and a history of difficult intubation.

The aim with history taking is to identify conditions known to be associated with difficult airways. Such associations are: ${ }^{3}$

- Previous difficult airway

- History of snoring

- Previous neck trauma, surgery or radiation

- Previous trauma or surgery of the temporomandibular joint

- Comorbidities such as:

- Ankylosing spondylitis

- Rheumatoid arthritis

- Degenerative osteo-arthritis

- Diabetes

- Genetic conditions such as:

- Pierre Robin syndrome

- Goldenhar syndrome

- Treacher Collins syndrome

- Down syndrome

- Lingual tonsil or tonsillar hypertrophy

- Subglottic stenosis

Features associated with a potential difficult airway: ${ }^{1,6}$

- Mallampati 3-4

- Thyro-mental distance $<6 \mathrm{~cm}$
- Mouth opening $<4 \mathrm{~cm}$

- Poor flexion/extension of the neck

- $\mathrm{BMI}>35$

- Neck circumference $>50 \mathrm{~cm}$

- Poor dentition

- Presence of a beard

- Distortion of facial anatomy e.g. facial trauma or tumours

- Intra-oral masses

\section{Management of the unanticipated difficult airway}

The difficult airway society had released the newest version of their guidelines in 2015. Below is their guideline for the management of the unanticipated difficult airway in adult patients:

During Plan A, the focus is on making the conditions as optimal as possible. With airway management, the first attempt is associated with the best chance at succeeding. ${ }^{4,8,9}$ With every additional attempt, the chance of success decreases and the risk of airway trauma and oedema increases. The society advocates a maximum of 3 attempts at intubation with a possible $4^{\text {th }}$ attempt by a more experienced provider. It is important to change something that may improve your chance of success between each attempt. This may include changing the position of the patient, changing the laryngoscope blade to a different

\section{DAS Difficult intubation guidelines - overview}

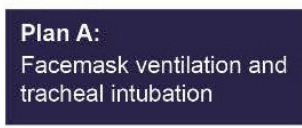

Plan B:

Maintaining oxygenation SAD insertion

\section{Plan C:}

Facemask ventilation
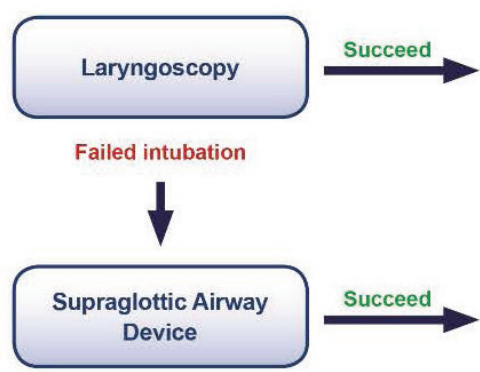

Failed SAD ventilation

$\downarrow$

Final attempt at face mask ventilation

cico

\section{Plan D:}

Emergency front of neck

access

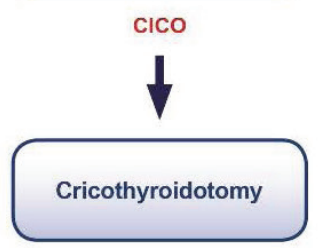


size or type, using an introducer or bougie, using a different size endotracheal tube, etc. ${ }^{4}$

Proper positioning of the patient is important to ensure success. ${ }^{3-5}$ The neck should be extended and the head flexed to achieve the so-called "sniffing-postion". For obese patients, the "ramped position" may be preferred where the external auditory meatus is at the same level as the sternal manubrium. This is achieved by putting pillows under the patients' shoulders. A 20$30^{\circ}$ head up position is especially beneficial in obese and pregnant patients as it increases the functional residual capacity (FRC) and is associated with an increase in the time to desaturation $\left(\mathrm{SpO}_{2}\right.$ $<90 \%$ ) by a mean of 103 seconds. ${ }^{10,11}$ The level of the bed should be at a comfortable height and possibly as high as the xiphoid process or even the nipple line of the anaesthetist. ${ }^{12}$

The next important aspect is adequate preoxygenation. This allows for a longer apneic time as the functional residual capacity (FRC) is filled with oxygen rather than nitrogen. Total body oxygen store increases from about 1.2 liters before preoxygenation to about 3.2 liters after 1 minute and 4.8 liters after 3 minutes. $^{10}$ The recommended time for pre-oxygenation is 3 minutes. Another endpoint to preoxygenation is to continue preoxygenation with a tight fitting mask $^{13}$ till the endtidal oxygen fraction is above $0.87 . .^{14}$

Adequate neuromuscular blockade can make airway management easier. ${ }^{5}$ People are often scared to give a second dose of suxametonium or to give a longer acting muscle relaxant when faced with a difficult airway. Intuitively, one would rather want the patient to return to spontaneous ventilation as soon as possible. However, adequate relaxation can help in creating better conditions for facemask ventilation, intubation and even supra-glottic airway airway insertion. With suggamadex now available in South Africa, a dose of Rocoronium can rapidly be reversed if the need exists for rapid reversal of the neuromuscular blockade.

While there is still a role for cricoid pressure in rapid sequence induction, it can also make intubation more difficult especially if applied incorrectly. ${ }^{4,5}$ When the view of the laryngeal inlet is obscured, cricoid pressure should temporarily be released to see if the view will improve. Various other external manuevers such as BURP (Backward, Upward, Rightward Pressure) had also been described to help in creating a better line of vision. ${ }^{4}$

Plan B aims to maintain oxygenation by returning to gentle facemask ventilation, followed by an attempt to insert a supraglottic airway device. The maximum number of attempts for insertion of supraglottic airway device is again 3 times, after which one should proceed to plan C. Cricoid pressure should be released when attempting to insert a SGA, as cricoid pressure decreases the oropharyngeal space. ${ }^{4}$

Second generation airway devices such as the ige ${ }^{\circledR}$, LMA Proseal ${ }^{\circledR}$ and LMA Supreme ${ }^{\circledast}$ are preferred due to their ability to separate the gastro-intestinal tract from the airways. Ventilation through the SGA should be assessed by demonstrating adequate tidal volumes on the ventilator and clinically there should not be a leak around the cuff. If ventilation through the SGA is adequate, one has to decide how to proceed. The first option is to wake the patient up and reschedule the surgery with an advanced plan for known difficult airway in place. The second option is to proceed with the surgery and continued ventilation through the SGA. The third option is to attempt intubation through the SGA with the use of a fibre-optic scope. In exceptional cases, one might want to proceed straight to a surgical airway.

Plan C is a brief re-attempt at facemask ventilation. If facemask ventilation succeeds, the patient should be woken up and an awake intubation planned. If there is not rapid success at facemask ventilation with improvement in oxygenation, plan D should immediately be activated.

Plan D is a surgical airway to achieve oxygenation. Cricothyroidotomy should be performed as a matter of urgency. Surgical cricothyroidotomy is preferred over needle cricothyroidotomy. Needle cricothyroidotomy requires high pressure to insufflate oxygen into the airway. This has the potential to cause trauma to the tracheal mucosa.

\section{The Obstetric Airway}

The risk for a difficult airway in a parturient is up to 8 times higher than the general population. ${ }^{15}$ The incidence varies from 1:238 to $1: 750$ general anaesthetics for obstetric patients with the most common quoted figure being 1:250.15 There are a variety of factors that makes the obstetric airway more challenging. These factors can be divided into maternal, fetal, surgical and situational factors. ${ }^{16}$

\section{Maternal factors}

Physiological changes during pregnancy account for most of the maternal factors. Pregnancy is associated with weight gain and studies have shown that this weight gain is associated with a change in the Mallampati score to a higher grade. ${ }^{16-20}$ Fluid retention can lead to airway oedema and this is exaggerated in pre-eclamptic patients. ${ }^{21}$ Oxytocinon infusion can also contribute to fluid retention. Eclamptic patients may sustain airway trauma during convulsions that leads to a swollen bleeding tongue. Patients are at risk of rapid desaturation as a result of a decreased FRC and the increase in oxygen consumption. FRC can decrease even further when the patient is supine. Oxygen consumption is increased by $25 \%$ from the non-pregnant state and can increase by up to $60 \%$ during labour. The patient is at high risk for aspiration due to multiple factors. The lower esophageal tone decreases under the influence of progesterone. The intra-gastric pressure increases. The gastric volume increases and the gastric content becomes more acidic. Gastric emptying is also delayed when the patient is in labour due to pain and opioid analgesics. It may be difficult to insert the blade because of enlarged breasts and obesity. Pregnant patients in the supine position have to be tilted laterally to avoid aorto-caval compression. This can lead to distortion of the line of vision.

\section{Situational factors}

With the advent of neuraxial techniques for caesarean section, general anaesthesia for surgical delivery happens increasingly less frequent. ${ }^{22-25}$ Teaching opportunities are lost ${ }^{26,27}$ so that trainees and junior doctors may find themselves in a difficult airway scenario without adequate experience in managing 
the situation. ${ }^{28}$ Situational anxiety may play a big role. General anaesthesia for caesarean section is most often indicated for sicker or bleeding parturients or extreme emergencies such as prolonged second stage, cord prolapse or severe fetal bradycardia. These situations in itself already put the anaesthetist under stress.

After-hour procedures are also associated with an increase incidence of difficult airway. In one study, up to $78 \%$ of difficult airways occurred after hours with about $69 \%$ occurring after 21:00 at night. Junior staff is more likely to encounter a difficult airway. ${ }^{15,22}$ Anaesthetists with less than 2 years experience had a 2.42 times higher risk of being involved in a difficult airway. With experience comes the ability to better predict the possibility of a complication and the ability to successfully manage the situation.

It comes as no surprise that emergency caesarean sections are associated with the highest risk of difficult airways. Emergency situations often lead to poor evaluation, poor planning, poor communication and poor performance.

\section{Fetal factors}

Fetal wellbeing is factor to consider for anaesthetists during Caesarean Section. A compromised mother will quickly lead to a compromised fetus or even fetal loss. It is therefor important to correct any hypoxaemia as soon as possible.

\section{Management of the obstetric airway}

The airway needs to be fully assessed even if the plan for anaesthesia is a neuraxial technique. Possible problems need to be identified. The risk of an unexpected difficult airway is ever present so a discussion with the patient and surgeon needs to be part of pre-operative management. Discuss what will happen if a difficult airway is encountered. Will the surgery go ahead or will the patient be woken up?

Confirm that aspiration prophylaxis had been given. The preferred aspiration prophylaxis in the parturient is a non-particulate such as sodium citrate $30 \mathrm{M} 30 \mathrm{ml}$ orally within 30 minutes of the procedure. ${ }^{31}$ Standard fasting guidelines should be adhered to for elective cases, while clear fluid should be allowed for women in labour. ${ }^{31}$ Position the patient supine with a left lateral tilt to avoid aorto-caval compression. A $20-30^{\circ}$ head-up position is beneficial ${ }^{10,11}$ as it increases the FRC, allowing the breasts to fall out of the way making it easier to insert the laryngoscope ${ }^{29}$ and it may potentially decrease the risk of aspiration. ${ }^{30}$ It is preferred that the patients be in the ramped position (external auditory meatus at the same level of the sternal manubrium).

Adequate pre-oxygenation is of utter importance to maximize the total body oxygen stores. ${ }^{10}$ There are differences in the classic teaching of preoxygenation. The common features include using a tight fitting mask ${ }^{13}$ with $100 \%$ oxygen. Some advocate the use of 8 vital capacity breaths ${ }^{4}$ whilst others pre-oxygenate for 3 minutes. ${ }^{4}$ Whatever technique is used, it is useful to gauge the

\section{Master algorithm - obstetric general anaesthesia and failed tracheal intubation}

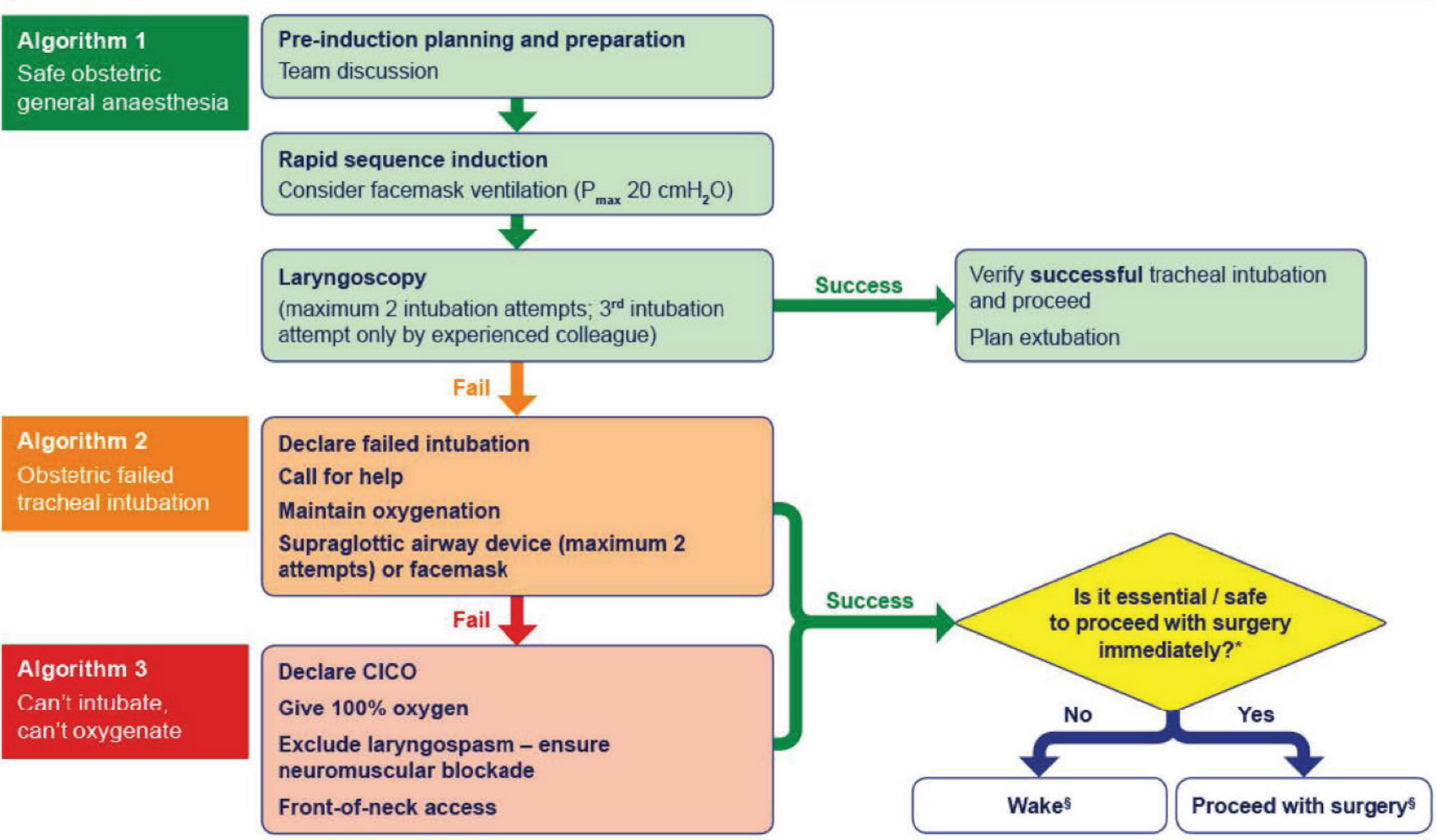

'Reproduced from Mushambi MC, Kinsella SM, Popat M, Swales H, Ramaswamy KK, Winton AL, Quinn AC. Obstetric Anaesthetists' Association and Difficult Airway Society guidelines for the management of difficult and failed tracheal intubation in obstetrics. Anaesthesia 2015; 70:1286 - 1306, with permission from Obstetric Anaesthetists' Association / Difficult Airway Society' 
adequacy of pre-oxygenation by accepting an end tidal oxygen concentration of more than $87-90 \% .{ }^{14}$

\section{Rapid sequence induction}

All parturients regardless of fasting status are at increased risk of aspiration and should get a rapid sequence induction. Cricoid pressure should be applied even though it decreases the lower esophageal sphincter tone. A force of $10 \mathrm{~N}$ should be applied while the patient is still awake and gradually be increased to $30 \mathrm{~N}$ as the patient falls asleep. Correctly applied cricoid pressure can aid in visualizing the laryngeal inlet. Wrongly applied cricoid pressure however can distort the anatomy and should be released if it compromises the line of vision.

A maximum of two attempts are allowed with a possible $3^{\text {rd }}$ attempt by a more experienced provider. Remember that the obstetric airway are prone to trauma and bleeding due to engorged submucosal blood vessels. Due to the small FRC, it is to be expected that hypoxia can rapidly occur. It is thus permissible to give gentle mask ventilation in between cases while maintaining cricoid pressure. Pressure during mask ventilation should not exceed $20 \mathrm{cmH}_{2} \mathrm{O}$.

Failing intubation after the second attempt means that a failed airway is present and should trigger the failed intubation protocol. (See algorithm 2) The next step is to try and maintain oxygenation either by returning to facemask ventilation or by attempting to insert a supra-glottic airway device. In this instance again a maximum of two attempts are permitted. At this point, you should be excluding laryngospasm and make sure that there is adequate muscle relaxation.

\section{Association / Difficult Airway Society}

The first manuever after failing intubation is to return back to facemask ventilation. If ventilation is difficult, simple airway manuevers should be tried. Oropharyngeal airways (OPA) may improve ease of ventilation. It is important to make sure that the correct size is used. Measure the size from the corner of the mouth to the If the OPA is too small, it will press against the tongue and cause airway obstruction. If the OPA is too big, it may go into the oesophagus leading to gastric inflation during ventilation. Two person mask technique may aid in ensuring a better seal for mask ventilation. ${ }^{4}$ Second generation supra-glottic airway devices (SGA) are the preferred option in the obstetric patient. These patients are at increased risk of aspiration. Second generation SGA have gastric ports. This allows for decompression of the stomach without soiling the airways.

Cricoid pressure should be released while the SGA is inserted. Cricoid pressure distorts the anatomy of the oropharynx and will make insertion of the SGA difficult.

If there is failure to oxygenate, it is prudent to convert to a surgical airway as soon as possible in order to prevent hypoxic injury to mother and baby. Failure to intubate per se doesn't kill patients, failure to oxygenate does!

\section{Algorithm 1- safe obstetric general anaesthesia}

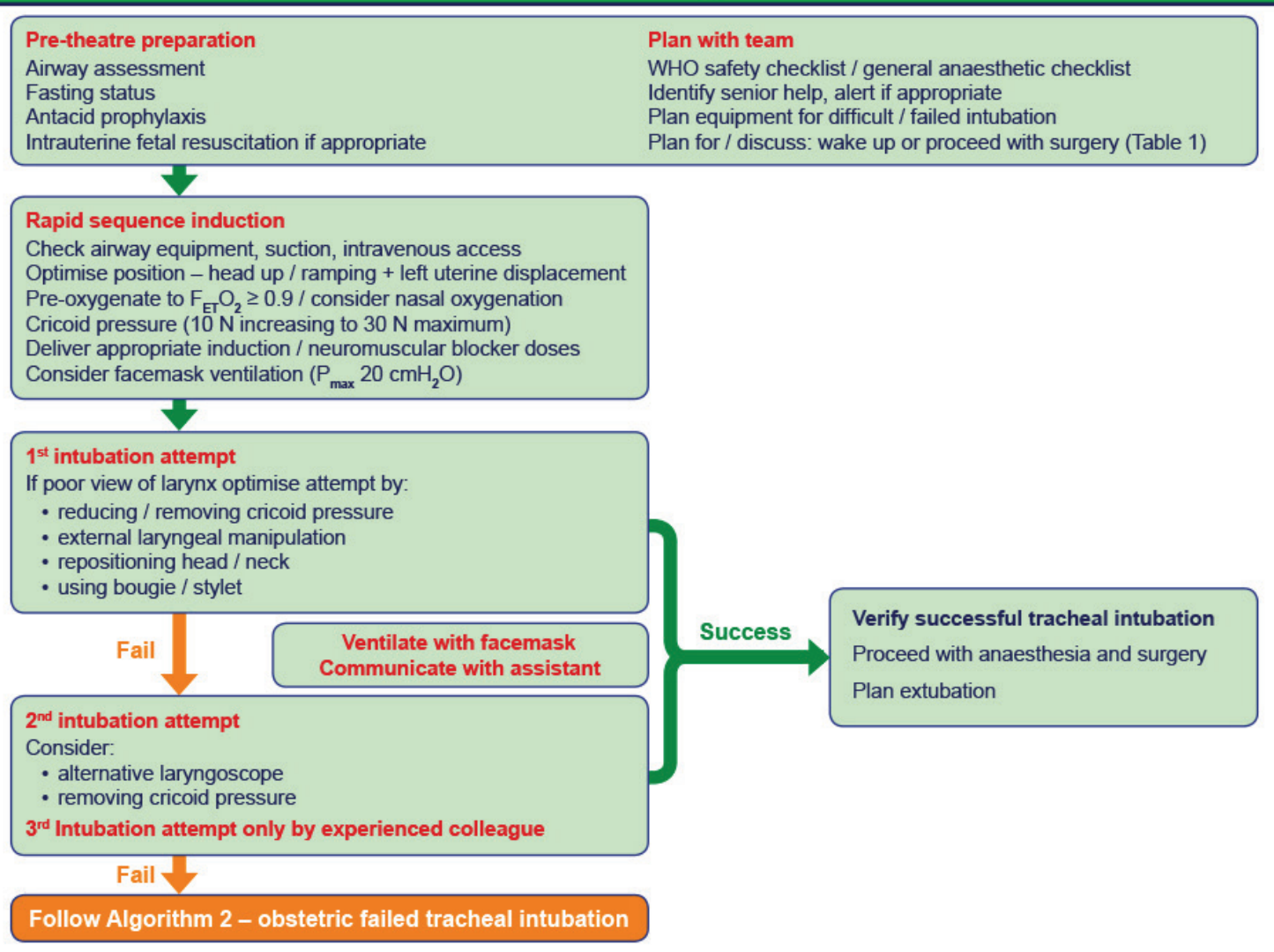

(c) Obstetric Anaesthetists' Association / Difficult Airway Society (2015)

'Reproduced from Mushambi MC, Kinsella SM, Popat M, Swales H, Ramaswamy KK, Winton AL, Quinn AC. Obstetric Anaesthetists' Association and Difficult Airway Society guidelines for the management of difficult and failed tracheal intubation in obstetrics. Anaesthesia 2015; 70:1286-1306, with permission from Obstetric Anaesthetists' Association / Difficult Airway Society' 


\section{Algorithm 2 - obstetric failed tracheal intubation}

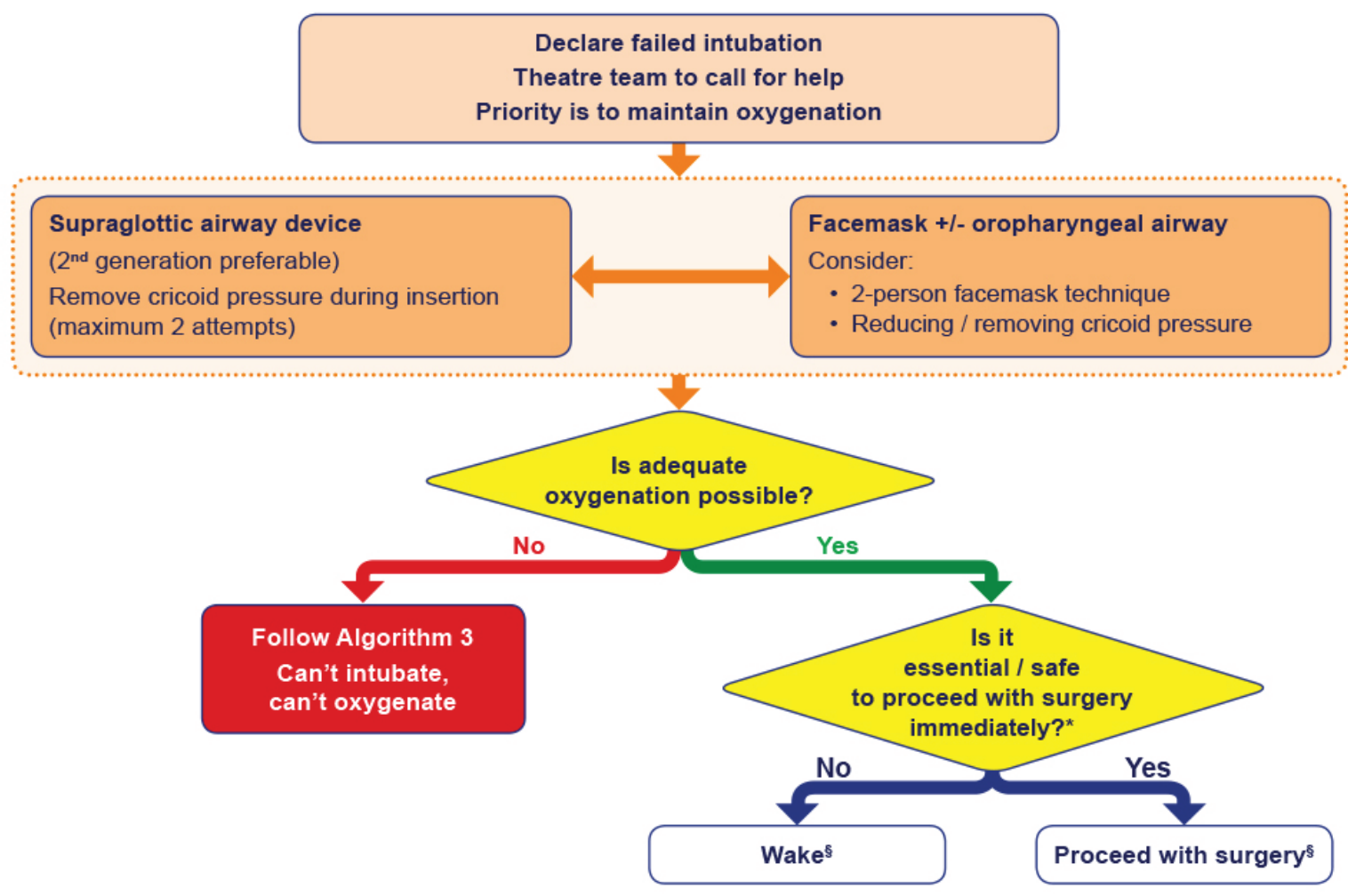

*See Table 1, \$See Table 2

(c) Obstetric Anaesthetists' Association / Difficult Airway Society (2015)

'Reproduced from Mushambi MC, Kinsella SM, Popat M, Swales H, Ramaswamy KK, Winton AL, Quinn AC. Obstetric Anaesthetists' Association and Difficult Airway Society guidelines for the management of difficult and failed tracheal intubation in obstetrics. Anaesthesia 2015; 70: 1286-1306, with permission from Obstetric Anaesthetists'

\section{Algorithm 3 - can't intubate, can't oxygenate}

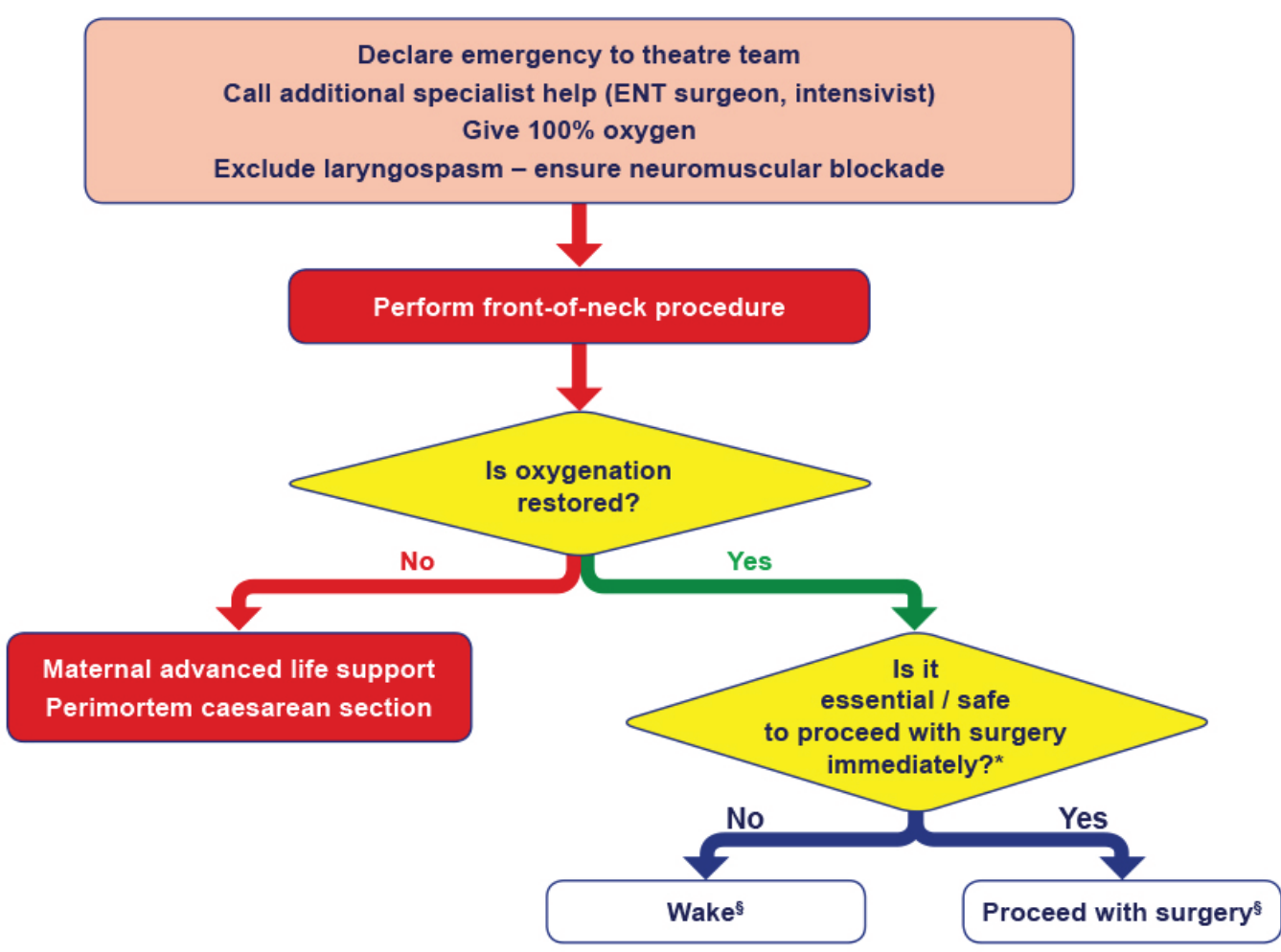

*See Table 1, §See Table 2

(C) Obstetric Anaesthetists' Association / Difficult Airway Society (2015)

'Reproduced from Mushambi MC, Kinsella SM, Popat M, Swales H, Ramaswamy KK, Winton AL, Quinn AC. Obstetric Anaesthetists' Association and Difficult Airway Society guidelines for the management of difficult and failed tracheal intubation in obstetrics. Anaesthesia 2015; 70: 1286 - 1306, with permission from Obstetric Anaesthetists' Association / Difficult Airway Society' 
A "can't intubate, can't ventilate" situation is probably one of the most scary situations anybody can find themselves in. Failure to quickly resolve the situation will have disasterous effects. If help hasn't been summoned before, it should be done as a matter of urgency. A cricothyroidotomy should be performed. There are two options: ${ }^{4}$ a non-surgical cricothyroidotomy where a large bore IV cannula can be advanced throught the cricothyroid membrane in a cannula-over-needle technique or a surgical cricothyroidotomy where a surgical incision is made through the cricothyroid membrane and a small endotracheal tube is advanced into the trachea. An oxygen source is then connected to the cannula or the endotracheal tube. A needle cricothyroidotomy (non-surgical) is associated with complications such as breath stacking, barotrauma, catheter kinking, or dislodgement, and does not provide airway protection with a cuff. A cricothyroidotomy is a temporary airway only even when a small endotracheal tube has been inserted.

If hypoxia persists, it may lead to cardio-pulmonary arrest. In such a case, resuscitation according to standard ACLS guidelines should commence. Important considerations in maternal resuscitation are the need to avoid aortocaval compression by displacement of the uterus. The baby should also be delivered as soon as possible in a peri-mortem caesarean section.

\section{Proceed with surgery or wake patient up?}

Every case will have to be evaluated on its own merits. Factors like the condition of the fetus and the mother will have to be considered. Other factors to think about are the resources that are available. A common doctrine is to say that the mom comes before the baby. When asking mothers about what they prefer in a situation where her life may be in danger if the procedure continues, a lot of mothers will rather allow harm to themselves for the benefit of the baby. Unfortunately you will not know the mothers' preference unless these difficult questions are dealt with before anaesthesia is commenced. This highlights the importance of proper preoperative evaluation and counseling and communication between all the members of the team.

\section{Conclusion}

Airway management is a central aspect of the anaesthetists' duties. The anaesthetist is regarded as an airway specialist and the expectation is that they should be able to manage any airway emergency. Proper airway evaluation is essential in planning the process of airway instrumentation and to identify the potential difficult airway. Even with proper evaluation, the potential for an unexpected difficult airway still exist. A failed airway is an anaesthetic emergency. Emergency scenarios are best managed when there is evidence based protocols in place so that there is a clear understanding amongst all the members of the team about what the next step will be. Such protocols should be clearly displayed in the operating room for easy reference.

\section{Table 1 - proceed with surgery?}

\begin{tabular}{|c|c|c|c|c|c|}
\hline \multicolumn{2}{|c|}{ Factors to consider } & \multirow{2}{*}{\begin{tabular}{|r|} 
WAKE \\
- No compromise
\end{tabular}} & \multirow{2}{*}{ - Mild acute compromise } & \multirow[b]{2}{*}{$\begin{array}{l}\text {-Haemorrhage responsive to } \\
\text { resuscitation }\end{array}$} & PROCEED \\
\hline \multirow{7}{*}{ 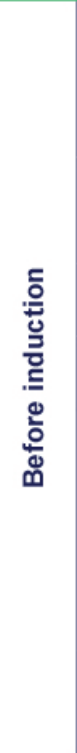 } & Maternal condition & & & & $\begin{array}{l}\text { - Hypovolaemia requiring } \\
\text { corrective surgery } \\
\text { - Critical cardiac or } \\
\text { respiratory compromise, } \\
\text { cardiac arrest }\end{array}$ \\
\hline & Fetal condition & - No compromise & $\begin{array}{l}\text { - Compromise corrected with } \\
\text { intrauterine resuscitation, } \\
\mathrm{pH}<7.2 \text { but }>7.15\end{array}$ & $\begin{array}{l}\text { - Continuing fetal heart rate } \\
\text { abnormality despite intrauterine } \\
\text { resuscitation, } \mathrm{pH}<7.15\end{array}$ & $\begin{array}{l}\text { - Sustained bradycardia } \\
\text { - Fetal haemorrhage } \\
\text { - Suspected uterine rupture }\end{array}$ \\
\hline & Anaesthetist & - Novice & -Junior trainee & -Senior trainee & - Consultant / specialist \\
\hline & Obesity & - Supermorbid & -Morbid & - Obese & - Normal \\
\hline & Surgical factors & $\begin{array}{l}\text { - Complex surgery or } \\
\text { major haemorrhage } \\
\text { anticipated }\end{array}$ & $\begin{array}{l}\text { - Multiple uterine scars } \\
\text { - Some surgical difficulties } \\
\text { expected }\end{array}$ & - Single uterine scar & - No risk factors \\
\hline & Aspiration risk & - Recent food & $\begin{array}{l}\text { - No recent food } \\
\text { - In labour } \\
\text { - Opioids given } \\
\text { - Antacids not given }\end{array}$ & $\begin{array}{l}\text { - No recent food } \\
\text { - In labour } \\
\text { - Opioids not given } \\
\text { - Antacids given }\end{array}$ & $\begin{array}{l}\text { - Fasted } \\
\text { - Not in labour } \\
\text { - Antacids given }\end{array}$ \\
\hline & $\begin{array}{l}\text { Alternative anaesthesia } \\
\text { - regional } \\
\text { - securing airway awake }\end{array}$ & - No anticipated difficulty & -Predicted difficulty & - Relatively contraindicated & $\begin{array}{l}\text { - Absolutely contraindicated } \\
\text { or has failed } \\
\text { - Surgery started }\end{array}$ \\
\hline \multirow{2}{*}{ 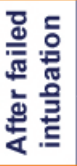 } & $\begin{array}{l}\text { Airway device / } \\
\text { ventilation }\end{array}$ & $\begin{array}{l}\text { - Difficult facemask } \\
\text { ventilation } \\
\text { - Front-of-neck }\end{array}$ & $\begin{array}{l}\text {-Adequate facemask } \\
\text { ventilation }\end{array}$ & $\begin{array}{l}\text { - First generation supraglottic } \\
\text { airway device }\end{array}$ & $\begin{array}{l}\text {-Second generation } \\
\text { supraglottic airway device }\end{array}$ \\
\hline & Airway hazards & $\begin{array}{l}\text { - Laryngeal oedema } \\
\text { - Stridor }\end{array}$ & $\begin{array}{l}\text {-Bleeding } \\
\text { - Trauma }\end{array}$ & -Secretions & - None evident \\
\hline
\end{tabular}

Criteria to be used in the decision to wake or proceed following failed tracheal intubation. In any individual patient, some factors may suggest waking and others proceeding. The final decision will depend on the anaesthetist's clinical judgement.

(C) Obstetric Anaesthetists' Association / Difficult Airway Society (2015)

'Reproduced from Mushambi MC, Kinsella SM, Popat M, Swales H, Ramaswamy KK, Winton AL, Quinn AC. Obstetric Anaesthetists' Association and Difficult Airway Society guidelines for the management of difficult and failed tracheal intubation in obstetrics. Anaesthesia 2015; 70:1286-1306, with permission from Obstetric Anaesthetists' Association / Difficult Airway Society' 


\section{Table 2 - management after failed tracheal intubation}

\section{Wake}

\section{- Maintain oxygenation}

- Maintain cricoid pressure if not impeding ventilation

- Either maintain head-up position or turn left lateral recumbent

- If rocuronium used, reverse with sugammadex

- Assess neuromuscular blockade and manage awareness if paralysis is prolonged

- Anticipate laryngospasm / can't intubate, can't oxygenate

\section{After waking}

- Review urgency of surgery with obstetric team

- Intrauterine fetal resuscitation as appropriate

- For repeat anaesthesia, manage with two anaesthetists

- Anaesthetic options:

a Regional anaesthesia preferably inserted in lateral position

a Secure airway awake before repeat general anaesthesia

\section{Proceed with surgery}

- Maintain anaesthesia

- Maintain ventilation - consider merits of:

a controlled or spontaneous ventilation

a paralysis with rocuronium if sugammadex available

- Anticipate laryngospasm / can't intubate, can't oxygenate

- Minimise aspiration risk:

- maintain cricoid pressure until delivery (if not impeding ventilation)

a after delivery maintain vigilance and reapply cricoid pressure if signs of regurgitation

- empty stomach with gastric drain tube if using second-generation supraglottic airway device

$\checkmark$ minimise fundal pressure

$\checkmark$ administer $\mathrm{H}_{2}$ receptor blocker i.v. if not already given

- Senior obstetrician to operate

- Inform neonatal team about failed intubation

- Consider total intravenous anaesthesia

'Reproduced from Mushambi MC, Kinsella SM, Popat M, Swales H, Ramaswamy KK, Winton AL, Quinn AC. Obstetric Anaesthetists' Association and Difficult Airway Society guidelines for the management of difficult and failed tracheal intubation in obstetrics. Anaesthesia 2015; 70: 1286 - 1306, with permission from Obstetric Anaesthetists' Association / Difficult Airway Society'

\section{References}

1. Toshiya Shiga, Zen'ichiro Wajima, Tetsuo Inoue. Predicting Difficult Intubation in Apparently Normal Patients. A Metaanalysis of Bedside Screening Test Performance. Anesthesiology 2005; 103:429-437

2. Crosby ET, Cooper RM, Douglas MJ, et al. Special article: The unanticipated difficult airway with recommendations for management. Can J Anaesth 1998; 45(8):757-776

3. Apfelbaum JL, Hagberg CA, Caplan RA, et al. Practice Guidelines for Management of the Difficult Airway. An Updated Report by the American Society of Anesthesiologists Task Force on Management of the Difficult Airway. Anesthesiology 2013; 118(2): 251-270

4. Law JA, Broemling N, Cooper RM, et al. The difficult airway with recommendations for management - Part 1 - Difficult tracheal intubation encountered in an unconscious/ induced patient. Can J Anaesth. 2013:60(11):1089-1118

5. Frerk C, Mitchell VS, McNarry AF, et al. Difficult Airway Society 2015 guidelines for management of unanticipated difficult intubation in adults. Br J of Anaesth 2015; 115(6):827-48

6. El-Ganzouri AR, McCarthy RJ, Tuman KJ, et al. Preoperative airway assessment: Predictive Value of a Multivariate Risk Index. Anesth Analg 1996; 82: 1197-204

7. Mallampati $S R$, Gatt $S P$, Gugino $L D$, et al. A clinical sign to predict difficult tracheal intubation: a prospective study. Can J Anaesth 1985; 32:429-34

8. Connelly NR, Ghandour $K$, Robbins $L$, et al. Management of unexpected difficult airway at a teaching institution over a 7 year period. J Clin Anest 2006; 18:198-204

9. Sakles JC, Chiu S, Mosier J, et al. The importance of first pass success when performing orotracheal intubation in the emergency department. Acad Emerg Med 2013:20:71-78

10. Lane $S$, Saunders $D$, Schofield A. A prospective randomized controlled trial comparing the efficacy of preoxygenation in $20^{\circ}$ head up vs. supine position. Anaesth 2005; 60(11):1064-1067

11. Hignette $R$, Fernando $R$, McGlenman $A$, et al. Does a $30^{\circ}$ head-up position in term parturients increase functional residual capacity? Implications for general anaesthesia. Int J Obs Anaesth 2008;17:S5

12. Lee HC, Yun MJ, Hwang JW, et al. Higher operating tables provide better laryngeal views for tracheal intubation. Br J Anaesth. 2014: 112(4):749-55

13. McGowan $P$, Skinner A. Preoxygenation - the importance of a good face mask seal. $B r$ J Anaesth 1995; 75:777-8

14. Tanoubi I, Drolet P, Donati F. Optimizing preoxygenation in adults. Can J Anaesth. 2009; 56:449-66

15. Quinn AC, Milne $D$, Columb $M$, et al. Failed tracheal intubation in obstetric anaesthesia: 2 year national case-control study in the UK. Br J Anaesth. 2013;110(1):74-80
16. Mushambi MC, Kinsella SM, Popat M, et al. Obstetric Anaesthetists' Association and Difficult Airway Society guidelines for the management of difficult and failed intubation in obstetrics. Anaesthesia 2015; 70(11):1286-1306

17. Chassard D, Le Quang D. Mallampati score during pregnancy. Br J Anaesth. 2012; 108:S2:ii200

18. Pilkington S, Carli F, Dakin MJ, et al. Increase in Mallampati score during pregnancy. $\mathrm{Br}$ J Anaesth. 1995; 74:638-42

19. Kodali BS, Chandrasekhar S, Bulich $L N$, et al. Airway changes during labor and delivery. Anesthesiology 2008; 108:357-62

20. Bryssine B, Chassard D, Le Quang D. Neck ultrasonography and mallampati scores in pregnant patients. Br J Anaesth. 2012; 180: S2:ii200

21. Rucklidge $M$, Hinton C. Difficult and failed intubation in obstetrics. Contin Educ Anaesth Crit Care Pain 2012; 12(2):86-91

22. Hawthorne I, Wilson $\mathrm{R}$, Lyons $\mathrm{G}$, et al. Failed intubation revisited: 17-year experience in a teaching maternity unit. Br J Anaesth. 1996; 76(5):680-684

23. Rahman K, Jenkins JG. Failed tracheal intubation in obstetrics: no more frequent but still managed badly. Anaesthesia 2005; 60:168-71

24. Johnson RV, Lyins GR, Wilson RC, et al. Training in obstetric general anaesthesia: A vanishing art? Anaesthesia 2000; 55:179-83

25. Tsen LC, Pitner R, Camann WR. General Anaesthesia for cesarean section at a tertiary care hospital 1990-1995: Indications and Implications. Int J Obstet Anesth 1998; 7:147-52

26. Searle RD, Lyons $\mathrm{G}$. Vanishing experience in training for obstetric general anaesthesia: An observational study. Int J Obstet Anesth 2008; 17:233-7

27. Smith NA, Tandel A, Morris RW. Changing patterns in endotracheal intubation for anaesthesia trainees: a retrospective analysis of 80,000 cases over 10 years. Anaesthesia and Intensive Care 2011; 39:585-9

28. Swales $\mathrm{H}$, Mushambi M, Winton a, et al. Management of failed intubation and difficult airways in UK obstetric units: an OAA survey. Int J Obstet Anesth 2014; 23:S19

29. Lee BJ. Kang JM, Kim DO. Laryngeal exposure during laryngoscopy is better in the 25 degrees back-up poistion than in supine position. Br J Anaesth. 2007; 99:581-6

30. Vanner R. Cricoid pressure. Int J Obstet Anaesth. 2009; 18:103-5

31. Hawkins JL, Arens JF, Bucklin BA, et al. Practice guidelines for Obstetric Anesthesia. An Updated Report by the American Society of Anesthesiologists Task Force on Obstetric Anesthesia. Anesthesiology 2007; 106:843-63 